\title{
In Vitro Morphogenesis Responses of Various Explant in Physalis angulata $\mathrm{L}$.
}

\author{
Retno Mastuti*, Aminatun Munawarti \\ ${ }^{1}$ Department of Biology, Faculty of Mathematics and Natural Sciences, University of Brawijaya, Malang, Indonesia
}

\begin{abstract}
The objective of this research was to identify morphogenesis responses of in vivo and in vitro-derived explant of Physalis angulata L. Explants were cultured on MS medium containing 3\% sucrose solidified with $1.3 \%$ agar supplemented with combination of 6-benzylaminopurine (BAP), indole acetic acids (IAA), naphthalene acetic acid (NAA) and 2,4-dichlorophenoxyacetic acid (2,4-D). All explant types have morphogenesis ability. Capability for shoot regeneration was observed in high number of shoot tip (96.1\%) and nodes explants $(75.2 \%)$. Callus formation was dominantly produced by in vitro leaf explants. In vivo leaf had low responses for shoot/root regeneration and callus formation. These results provided an alternative choice of the explant suitable for either plant regeneration or callus formation.
\end{abstract}

Keywords: callus, cotyledonary nodes, explant types, shoot regeneration.

\section{INTRODUCTION}

Herbal medicine has been used for centuries to treat various problems of health conditions. A lot of medicinal plants have been used to treat illness and promote health. Physalis angulata L. is a member of Solanaceae family which has been widely used for traditional medicine [1]. A wide variety of species have different and specific herbal characters. As herbal medicine this plant is used to cure various disorders like asthma, kidney, bladder, jaundice, gout, inflammations, cancer, digestive problems and diabetes [2]. Physalis angulata has also been reported has antimicrobial [3] and antiparasitic activity [4].

Increasing interest to $P$. angulata is not accompanied by their availability in high number. Generally $P$. angulata is grow wild in the waste land, near road, in the forest and cultivated field. In addition this plant has not been widely cultivated. High exploitation of this plant will lead to extinction. This plant is generatively propagated through seeds which take a time to yield a mature plant. Therefore the alternative technique to produce a lot of regenerated plants in a relative short time is necessary.

Plant tissue culture is micropropagation technique which can be initiated by various tissues as explant. The most commonly used explants are shoot tips, organ, and axillary bud or meristem. Shoot regeneration of $P$. minima were initiated

\footnotetext{
* Correspondence address:

Retno Mastuti

Email : mastuti7@ub.ac.id

Address : Dept. Biology, Faculty of Mathematics and Natural Sciences, University of Brawijaya, Veteran Malang, Malang 65145.
}

from leaf, shoot tips and root explants [5]. While the efficient in vitro regeneration of $P$. peruviana was achieved from node, internode and leaf explants [6]. High number in vitro shoots of $P$. angulata has been produced by axillary meristem [7] and leaf disc explants [8]. This study was to identify the potential of in vivo and in vitro explant types of $P$. angulata in shoot/root regeneration through in vitro system. This knowledge is expected to support the efforts to conserve biodiversity of medicinal plants especially $P$. angulata.

\section{MATERIALS AND METHODS \\ Plant materials and explant source}

Explants were derived from in vivo plants and in vitro tissue culture. In vivo explant was young leaf derived from wild grown $P$. angulata plant in the maize field. In vitro nodes and leaves were obtained from three weeks old shoot culture while shoot tips were derived from two weeks old in vitro seedling.

\section{Surface sterilization of in vivo explants}

Young leaf was excised from plant source and washed thoroughly in running tap water for 30 min. Further, it was surface sterilized with $70 \%$ (v/v) ethyl alcohol (30 sec) followed by $10 \%(v / v)$ Clorox (10 $\mathrm{min}$ ) in Laminar Air Flow under aseptic conditions. Finally, leaf explants were rinsed thoroughly (3 times) with sterilized aquadest for $5 \mathrm{~min}$ each to remove traces of Clorox.

\section{Medium and culture conditions}

All explant types were cultured on MS salt basal medium [9] with a source of carbon sugars 30 g. $\mathrm{L}^{-1}$ and solidified with agar $13 \mathrm{~g} . \mathrm{L}^{-1}$. Combina- 
tions of cytokinin (BAP, Kinetin) and auxin (IAA, 2,4-D and NAA) were used to observe morphogenesis responses and the potency of explant to produce shoot. The media was adjusted to $\mathrm{pH} 5.8$ by adding $\mathrm{NaOH} / \mathrm{HCl} 0.1 \mathrm{~N}$ and sterilized by autoclave at $121^{\circ} \mathrm{C}, 1 \mathrm{~atm}$ for $15 \mathrm{~min}$. All cultures were maintained in continuous light intensity of 600 lux at a temperature of $22 \pm 2^{\circ} \mathrm{C}$.

\section{Culture initiation stage}

All explant types were cultured in Benzyl adenine (BA) $\left(1,3,4 \mathrm{mg} \cdot \mathrm{L}^{-1}\right)+$ IAA $0.1 \mathrm{mg} \cdot \mathrm{L}^{-1}$; BAP 3.5 $\mathrm{mg} \cdot \mathrm{L}^{-1}+$ Kinetin $0.4 \mathrm{mg} \cdot \mathrm{L}^{-1}$ and BAP $2 \mathrm{mg} \cdot \mathrm{L}^{-1}+2,4-$ D $0.1 \mathrm{mg} \cdot \mathrm{L}^{-1}$ to observe the response of cultured explants. The sterilized in vivo leaf was cut into $\pm 0.5 \mathrm{~cm}^{2}$ pieces. Each piece was laid upon the medium with its abaxial side face the medium surface. While in vitro leaf was cultured as a whole with the same orientation. Nodes and shoot tip were cultured in media in an upright position. Each experiment was repeated thrice with three replicates. High shoot produced explants were selected and cultured into shoot multiplication medium containing combination of $B A P+N A A, B A P+2,4-D, B A P+I A A$ and $B A P+K i n$.

\section{Shoot multiplication}

The explant type showed high percentage of morphogenesis or organogenesis response in culture initiation stage was selected to culture in shoot multiplication medium containing BAP combined with other cytokinin (kinetin) and auxin, namely BAP $0.1 \mathrm{mg} \cdot \mathrm{L}^{-1}+\mathrm{NAA} 0.5 \mathrm{mg} \cdot \mathrm{L}^{-1}$; BAP 2 mg. $L^{-1}+2,4-D 0.1$ mg. $L^{-1}$; BAP (3.5 and 4 mg. $\left.\mathrm{L}^{-1}\right)+$ Kin $0.4 \mathrm{mg} \cdot \mathrm{L}^{-1}$ and $\operatorname{BAP}(0.5 ; 1.0 ; 3.0$; $4.0 \mathrm{mg} \cdot \mathrm{L}^{-1}+$ IAA $0.1 \mathrm{mg} \cdot \mathrm{L}^{-1}$. Shoot number was recorded after 4 weeks of culture.

\section{RESULT AND DISCUSSION Initiation stages}

Shoot and root regeneration were observed in all explant types except for shoot tips. Almost all (96\%) shoot tips were capable of shoot regeneration but there was no shoot tips that produced root (Fig. 1). Nodes not only showed high frequency of shoot $(75.2 \%)$ and root $(57.1 \%)$ regeneration but also callus formation (38.9\%). High number of in vitro leaf explants produced callus in almost medium tested. Callus formation was observed in $51.8 \%$ in vitro leaf explants which more dominant than shoot $(35.7 \%)$ and root $(7.1 \%)$ regeneration. Callus formation in basal leaf blade apparantly is due to active cellular growth of wounding respons (Fig. 3C). In vivo leaf explants showed low frequency of shoot $(5.6 \%)$ and root $(10.1 \%)$ organogenesis as well as of callus formation (11.1\%). In the combination of cytokinin:auxin the in vitro shoot tips and nodes had high response in shoot induction and regeneration than in vitro and in vivo leaf explants.

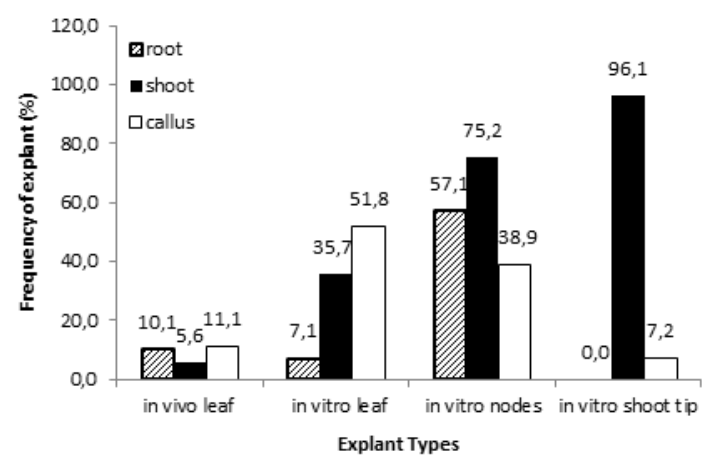

Figure 1. Frequency of morphogenesis response (shoot root organogenesis and callus formation) derived from different types of explant

Organogenesis response of all explant types was influenced by plant growth regulator (PGR) supplemented in culture medium. High percentages of shoot tips and nodes explant regenerated shoots in all combination of PGR (Fig. 2). Almost $100 \%$ of shoot tips were capable of producing shoot (Fig. 3A) in all types of culture media. Adventif shoots were also produced by $>90 \%$ nodes on media containing BAP ( 3 and $\left.4 \mathrm{mg}^{-1} \mathrm{~L}^{-1}\right)+$ IAA (0.1 mg. $\left.\mathrm{L}^{-1}\right)$ (Fig. 3B) and BAP (2 mg. $\left.\mathrm{L}^{-1}\right)+2,4-\mathrm{D}(1$ mg. $\left.L^{-1}\right)$. However, in the media supplemented by BAP $(1 \mathrm{mg} / \mathrm{L})+$ IAA $\left(0.1 \mathrm{mg} \cdot \mathrm{L}^{-1}\right)$ and BAP (3.5 mg. $\left.\mathrm{L}^{-1}\right)+$ Kin $\left(0.4 \mathrm{mg} \cdot \mathrm{L}^{-1}\right)$ shoots was only produced by $<50 \%$ of nodes explant. Shoots were only produced by $5.6 \%$ of in vivo leaf (Fig. $3 \mathrm{C}$ ) and $35.7 \%$ of in vitro leaf explants when they were cultured in media containing BAP $\left(4 \mathrm{mg}^{-\mathrm{L}^{-1}}\right)+$ IAA (0.1 mg. $\mathrm{L}^{-1}$ ). These results indicated that combination of $B A P+I A A, B A P+K i n$ and $B A P+2,4-D$ were suitable for promoting shoot regeneration in nodes and shoot tips explants.

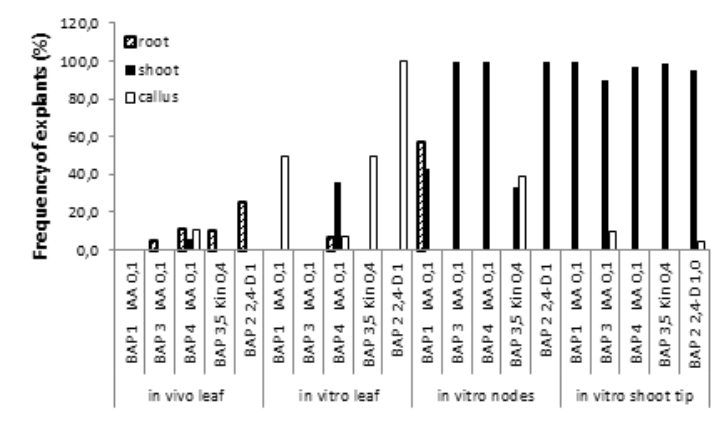

Explant types in various combination of cytokinin:auxin

Figure 2. Frequency of morphogenesis response of four explant types in various combination of cytokinin:auxin 

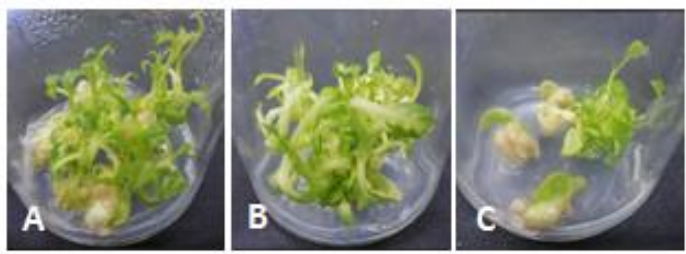

Figure 3. Shoot multiplication of $P$. angulata derived from different explant types in shoot induction medium after 4 weeks of culture. A. shoot tips explant, B. nodes explant, C. in vitro leaf explant.

Type of explant is an important factor for the success of tissue culture methods $[10,11]$. Parts of plants commonly used as explants are stem, leaf, petiole, cotyledon and hypocotyls. Factors that affect the response of explants were: genotype, physiological condition of donor plants, source or origin of explants, and explant position on the donor plant. The different morphogenesis responses of each explant types on the same medium can be due to the different levels of endogenous growth hormone in the different types of explant [12]. Morphogenesis process is the formation of new cellular structures which is highly related to not only chemical modulators such as plant growth regulators, but also the competence levels of cell, physiological stage and performance of gene control [13]. It is related to competence of cell in answering signs of extrinsic and intrinsic factors which promote cell determination.

This results shows that shoot tip of in vitro seedling of $P$. angulata was superior to other types of explant for shoot induction. Low morphogenesis response $(<30 \%)$ of in vivo leaf explants is accordance with the statement of Yildiz [10] that explants derived from field have the low growth response.

\section{Shoot multiplication derived from shoot tips explants}

Since almost all shoot tips explants showed good responses to shoot regeneration (Fig. 2) therefore the effect of other PGR combinations was observed on its competence to shoot multiplication. Eight weeks after culture the number of shoot/explants ranges from 1.3 to 6.8 shoots/explant in all culture medium tested (Fig. 4). Combination of BAP + NAA produced shoots with the lowest number (1.3 shoots/explant) rather than any other PGR combinations. Explants cultured in medium BAP + NAA only produced single shoot and followed by root induction (Fig. 5A). The number of shoots produced in this medium was not significantly different from that produced by medium BAP 0.5 mg. $.^{-1}+$ IAA 0.1 mg. $L^{-1}$ (1.7 shoots/explant). However medium BAP + NAA promoted single shoot with wide leaf (Fig. 5D). Meanwhile, the other concentration of BAP+IAA could induce direct shoot regeneration with the relative similar number (4.9-6.8 shoots/explant) (Fig. 5BC, E-F). BA alone or combined with auxin also produced high shoot number in $P$. minima [1415] and $P$. peruviana [16]. High shoot number $(152.8 \pm 0.40)$ was produced by leaf disc explants of $P$. angulata in MS+BAP+IAA+GA 3 after the third subculture [8]. This results showed that shoot tips derived from in vitro seedling is potentially used as explants to support the development of micropropagation of $P$. angulata because the ability to regenerate shoot in various PGR combinations. Routine subculture should be done to obtained higher shoot number.

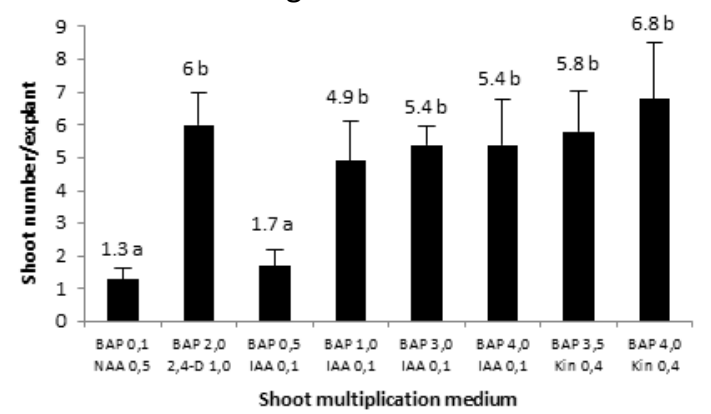

Figure 4. Shoot number derived from in in vitro shoot tips explants in various combinations of cytokinin: auxin eight weeks after culture. The number followed by the same letter are not significantly different at the $5 \%$ level (mean $\pm S D, n=3$ ).
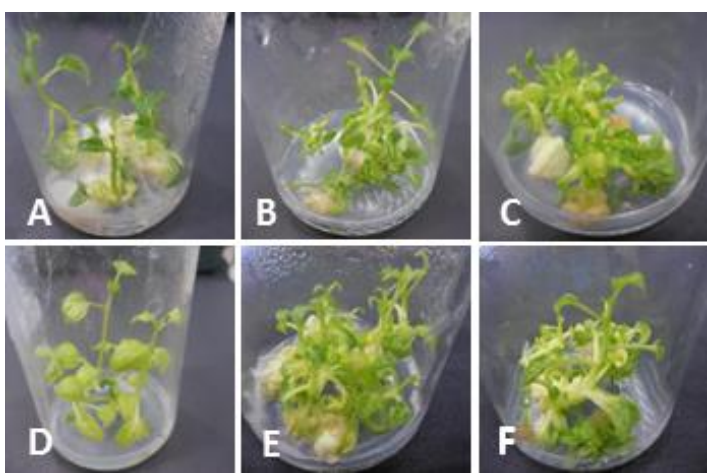

Figure 5. Shoot multiplication derived from in vitro shoot tip explants in various combination of hormone cytokinin:auxin eight weeks after culture.

A. BAP $0.1 \mathrm{mg} \cdot \mathrm{L}^{-1}+\mathrm{NAA} 0.5 \mathrm{mg} \cdot \mathrm{L}^{-1}$

B. BAP $2 \mathrm{mg} \cdot \mathrm{L}^{-1}+2,4-\mathrm{D} 1 \mathrm{mg} \cdot \mathrm{L}^{-1}$

C. BAP $4 \mathrm{mg} \cdot \mathrm{L}^{-1}+\mathrm{Kin} 0.4 \mathrm{mg} \cdot \mathrm{L}^{-1}$

D. BAP $0.5 \mathrm{mg} \cdot \mathrm{L}^{-1}+\mathrm{IAA} 0.1 \mathrm{mg} / \mathrm{L} \mathrm{mg} \cdot \mathrm{L}^{-1}$

E. BAP $1 \mathrm{mg} \cdot \mathrm{L}^{-1}+$ IAA $0.1 \mathrm{mg} \cdot \mathrm{L}^{-1}$

F. BAP $4 \mathrm{mg} \cdot \mathrm{L}^{-1}+\mathrm{IAA} 0.1 \mathrm{mg} \cdot \mathrm{L}^{-1}$ 


\section{CONCLUSION}

Shoot tip of $P$. angulata derived from in vitro seedling was the most responsive explant to shoot regeneration and mutiplication in various combination medium BA+auxin/cytokinin. On the contrary, in vivo leaf explant showed low respons in morphogenesis.

\section{ACKNOWLEDGEMENT}

The authors thank Mufidatur Rosyidah, S.Si., M.Si. for laboratory assistance. This research was supported by Directorate of Research and Community Service, Directorate General for Research and Development at the Ministry of Research, Technology and Higher Education 2017.

\section{REFERENCES}

[1] Rengifo-Sagalo, E., G. Vargas-Arana. 2013. Physalis angulata L. (Bolsa Mullaca): review of its traditional uses, chemistry and pharmacology. Boletin Latinoamericano y del Caribe de Plantas Medicines y Aromatica. 5. 431-445.

[2] Bano, A., H.S. Dhaliwal, V. Sharma. 2015. A pharmalogical comprehensive review on 'rassbharry' Physalis angulata L. Int J Pharm Pharm Sci. 8:30-34.

[3] Silva, M.T.G., S.M. Simas, T.G.F.M. Batistia, Cardarelli, T.C.B. Tomassinni. 2005. Studies on antimicrobial activity, in vitro of Physalis angulata L. (Solanaceae) fraction and physalin B bringing out the importance of assay determination. Mem. Inst. Oswaldo Cruz, Rio de Janeiro. 7. 779-782.

[4] Meira C.S., E.T. Guimaraes, J.A.F. dos Santos, D.R.M. Moreira, R.C. Nogueira, T.C.B. Tomassini, I.M. Ribeiro, C.V.C. de Souza, M.B.P. Soares. 2015. In vitro and in vivo antiparasitic activity of Physalis angulata L. concentrated ethanolic extract against Trypanosoma cruzi. Phytomedicin. 1. 969-974.

[5] Mungole, A.J., V.D. Doifode, R.B. Kamble, A. Chaturvedi, P. Zanwar. 2011. In vitro callus induction and shoot regeneration in Physalis minima L. Ann. Biol. Res. 2. 79-85.

[6] Ramar K, V. Ayyaduri, T. Arulprakash. 2014. In vitro shoot multiplication and plan regeneration oh Physalis peruviana L. an important medicinal plant. Int. J. Curr. Microbiol. App. Sci. 3. 456-464.

[7] Kumar, O.A., S. Ramesh, S.S. Tata. 2015 Establishment of a rapid plant regeneration system in Physalis angulata L. through axillary meristems. Not. Sci. Biol. 7(4). 471474.

[8] Kumar, O.A., S. Ramesh, S.S. Tata. 2016. In Vitro micropropagation of the medicinal plant Physalis angulata L. Not. Sci. Biol. 8(2). 161-163.

[9] Murashige, T., F. Skoog. 1962. A revised medium for rapid growth and bioassays with tobacco tissue cultures. Physiol. Plant. 15. 473-497.

[10] Yildiz, M. 2012. The prerequisite of the success in plant tissue culture: High frequency shoots regeneration. Recent advances in plant in vitro culture. In: Leva, A., L.M.R. Rinaldi (Eds). Recent Advances In Plant Tissue Culture. InTech Publ. 63-90. 10.5772/51097.

[11] Gikloo Elhami, B., M. Khosrowchahli. 2012. Effects of explant type, plant growth regulators and activated charcoal on direct organogenesis of Silybum marianum. Afr. J. Biotechnol. 37. 9023-9027.

[12] Quoirin, M., J.M. Bittencourt, F. Zanette, D.E. de Oliveira. 1998. Effect of growth regulators on indirect organogenesis of Acacia mearnsii tissues cultured in vitro. $R$. Bras. Fisiol. Veg. 2:. 101-105.

[13] Almeida, M., E.M. Graner, G.E. Brondani, L.S. Oliveira, F.A. Artioli, L.V. Almeida, G.F. Leone, F.J.B. Baccarin, P.O. Antonelli, G.M. Cordeiro, G.P.J. Oberschelp, K.D. BattaginPiotto. Plant morphogenesis: theorical bases. Adv. For. Sci. Cuiabd. 1.13-22.

[14] Intzaar, S., M. Akram, H. Afrasiab. 2013. High frequency multiple shoot formation of Pygmy Groundcherry (Physalis minima): an endangered medicinal plant. Int. J. Agric. Biol. 15. 755-760.

[15] Mungole, A.J., V.D. Doifode, R.B. Kamble, A. Chaturvedi, P. Zanwar. 2011. In vitro callus induction and shoot regeneration in Physalis minima L. Annals Biol. Res. 2.79-85.

[16] Ramar, K., V. Ayyadurai, A. Arulprakash. 2014. In vitro shoot multiplication and plant regeneration of Physalis peruviana L. An important medicinal plant. Int. J. Curr. Microbiol. App. Sci. 3. 456-464. 